\title{
CRISE DO ESTADO E JURISDIÇÃO
}

\author{
JEFERSON DYTZ MARIN ${ }^{1}$
}

\begin{abstract}
RESUMO: A percepção das crises do Estado na pós-modernidade, que deflagram a busca pela identidade perdida, bem como a compreensão histórica, examinando-se o papel ideológico da Jurisdição, decisivamente influenciada pelo modelo racionalista-liberal. Nesse contexto, o paradigma liberal-individualista registra um conflito permanente com o Estado Social, que privilegia a tutela dos direitos difuso-coletivos, asseguradores da isonomia. O Welfare State produziu aturadas mutações no modelo liberal, inserindo a igualdade no rol de direitos tutelados pelo Estado. A superação do paradigma privatista-formalista constitui-se no primeiro passo para a superação do conformismo provocado pelo liberalismo, que recolhe a força de trabalho da sociedade e oferta migalhas, estimulando a satisfação artificial de uma realidade excludente.
\end{abstract}

PALAVRAS-CHAVE: Crise; Estado; Jurisdição; Processo.

ABSTRACT: The article deals with the perception of the crisis of the State in post-modernity, which triggers the search for lost identity and historical understanding, examining the ideological role of jurisdiction, decisively influenced by the rationalist-liberal model. In this context, the liberal-individualist paradigm registers a permanent conflict with the welfare State, which favors the protection of diffuse-collective rights, guarantors of isonomy. The Welfare State has produced substantial mutations in the liberal model, inserting equality on the list of State-protected rights. Overcoming the privatist-formalist paradigm constitutes the first step in overcoming the resignation caused by liberalism, which collects the society's work force and offers back crumbs, encouraging the artificial satisfaction of an exclusionary reality.

KEYWORDS: Crisis; State; Jurisdiction; Process.

SUMÁRIO: 1. Crise, Estado e Jurisdição; 2. A Matriz Estatal Contemporânea e o Compromisso Racionalista do Processo; 3. A Perniciosidade da Certeza no Direito; Considerações Finais; Referências Bibliográficas.

SUMMARY: 1. Crisis, State and Jurisdiction; 2. The Contemporary State Matrix and Judicial procedure's rationalist compromise; 3 . The Prejudicial effect of Certainty in Law; Final Remarks; Bibliographic References.

Artigo recebido em 21.12.2010. Pareceres emitidos em 1․04.2011 e 4.04.2011.

Artigo aceito para publicação em 31.05.2011.

${ }_{1}^{1}$ Advogado. Doutor em Direito - UNISINOS/RS. Mestre em Direito - UNISC/RS. Professor da Graduação e Pós-Graduação da UCS/RS. Pesquisador CNPq da UCS/RS. Membro Honorário da Academia Brasileira de Processo Civil - ABDPC - Porto Alegre/RS. Diretor do IEM - Instituto de Estudos Municipais - Porto Alegre/RS. Membro do IHJ - Instituto de Hermenêutica Jurídica Porto Alegre/RS. jdmarin@ucs.br 


\title{
1. CRISE, ESTADO E JURISDIÇÃO
}

O século $X X$ firmou definitivamente a idéia de que o Estado enfrenta uma crise, especialmente no que toca à sua identidade. Essa busca da identidade perdida é um dos maiores desafios que vem se pondo na modernidade e, ao revés do alcance de uma solução, o Estado representa um número cada vez mais significativo e complexo de matizes, sendo que nenhum desses modelos revela-se capaz de atender às novas demandas sociais que vão surgindo.

O Estado Moderno, cujo surgimento deu-se a partir do século XVI, desde então, tem empreendido um processo de busca de seu locus e o fato de ter passado por sucessivas transformações acabou por impedir a identificação de uma evolução cronológica, que descurasse dos elementos espaciais e das dificuldades de implementação das propostas de modelos que foram paulatinamente erigidas. De qualquer sorte, se é bem verdade que um sem-número de agruras existem quando se busca dizer o que o Estado é hoje, também é verdade que existem pontos comuns no sentido de encontrar elementos que definitivamente não são contemplados pelo Estado Moderno. Nesse viés, as altercações weberianas de Giacomo Marramao, que aborda o tema da secularização do Estado:

\begin{abstract}
O desenvolvimento da moderna sociedade européia ocidental é representado - pela primeira vez explicitamente e de forma completa por Max Weber como "processo de secularização" (Säkularisationsprozess). Todavia, a adoção desta expressão é marcada por uma ambivalência estrutural: por um lado, ela remete a uma reconstrução geral unitária das vicissitudes da cultura do Ocidente, destinada a exercer forte influência sobre a reflexão posterior; por outro, porém, este mesmo programa "reconstrutivo" constitui-se em nítida ruptura com a filosofia da história do século XIX, seja em sua versão "idealista" (Hegel), seja na versão "materialista" (Marx). ${ }^{2}$
\end{abstract}

Por sinal, o desestado, a idéia de que o poder passou a integrar a sociedade, deixando aos poucos lugares cativos que tinha no Estado, também fez com que se repensasse o papel estatal. E, em que pese a posição firmada, no sentido de que a solução do Estado passa pelo Estado, pode-se ter, em ilação, de que o locus estatal ainda não alcançou contornos com caráter de definitividade. Aliás, muito pelo contrário, como afirmado antes, o Estado está em busca da identidade perdida. A crise passa, também, pela constatação de que o fisiologismo e o personalismo tornaram-se características correntes na modernidade, relegando o caráter programático de alternativas ao Estado a ator coadjuvante. No mais, a evolução tecnológica, em que pese os avanços que tenha patrocinado, fundou a burocratização do mundo e uma nova concepção do papel do homem nos processos desenvolvimentistas. Como pondera Ovídio Baptista da Silva:

${ }^{2}$ MARRAMAO, Giacomo. Céu e Terra. Traduzido por Guilherme Alberto Gomez de Andrade. São Paulo: UNESP, 1997. p. 47. 
A ambiciosa criação de um mundo social em que os homens não seriam mais dirigidos pelos homens, e sim pelas leis, acabou por submeter os homens às suas máquinas, conseqüência, de resto, imanente como tendência profunda, nas filosofias mecanistas [...]. ${ }^{3}$

Nessa esteira, premente o exame das crises do Estado Moderno, com o propósito de compreendê-lo e, também, estabelecer critérios na busca dessa identidade perdida.

A primeira das crises é a conceitual. A soberania do Estado, desde Rousseau, fulcra-se na vontade geral, que ampara a transferência de poder do povo ao soberano, com forte acento moral. O que ocorre, contudo, em face da atitude centrífuga ${ }^{4}$ de dispersão dos locais do poder e em face do surgimento das ONGs, associações, parcerias público-privadas e dos blocos econômicos, é a necessidade de um (re) pensar da soberania do Estado. Internamente, a descentralização há muito vem sendo implementada e externamente, a economia - sempre ela - impulsionou os países na busca do fortalecimento do papel negociador na esfera internacional, estabelecendo grupos de interesses. Dessa forma, a globalização exerce caráter mutante no esteio precípuo da definição do Estado, a soberania, dando azo ao chamado Estado-Região, que enfraquece o paradigma do Estado-Nação.

Noutra senda, o cunho universal dos direitos humanos também fez com que houvesse um "recuo" na idéia de soberania, já que a necessidade de fixação de um catálogo indiferente à realidade de cada país causou uma interferência direta nos princípios norteadores do Estado. Como dizem Bolzan e Streck, "os direitos humanos são universais e, cada vez mais se projetam no sentido de seu alargamento objetivo e subjetivo, mantendo seu caráter de temporalidade". ${ }^{5}$

A crise estrutural, por sua vez, funda-se nas dificuldades do Welfare State, que, parece, ainda é o modelo de Estado que oferece guarida mais sólida ao Estado Constitucional, já que, como assevera Angela Espindola, "o estado liberal, cuja semente foi burguesa, adotava a mesma retórica do Estado Absolutista, particularizada pela fundamentação da Soberania não em Deus (poder divino do monarca), mas antes no povo."

A crise estrutural do Welfare, a par da disparidade e unidade conceitual, firma-se, precipuamente, nas dificuldades apresentadas no custeio dos direitos sociais. Os governantes, por sua vez, têm buscado alternativas mediante a

\footnotetext{
${ }^{3}$ BAPTISTA DA SILVA, Ovídio Araújo. Processo e Ideologia: O Paradigma Racionalista. Rio de Janeiro: Forense, 2004: p. 117.

${ }^{4}$ STRECK, Lenio Luiz; MORAIS, José Luis Bolzan. Ciência Política e Teoria do Estado. 5 ed. Porto Alegre: Livraria do Advogado, 2006. p. 139.

${ }^{5}$ Idem, p. 146

${ }^{6}$ ESPINDOLA, Angela Araujo da Silveira. A Crise Conceitual e a (Re) Construção Interrompida da Soberania: O Fim do Estado-Nação? In: MORAIS, José Luis Bolzan (Org.). O Estado e suas Crises. Porto Alegre: Livraria do Advogado, 2005. p. 45.
} 
implementação de práticas idênticas e reiteradas, que passam pelo aumento da carga tributária, privatizações, concessões, parcerias público-privadas e reestruturação do aparato estatal, com vistas à diminuição de gastos do Erário, o que pode ser constado, por exemplo, através do programa PDV, implementado no Rio Grande do Sul pelo governo de Antonio Britto ou a demissão dos servidores da EMATER-ASCAR, ocorrida recentemente no governo Yeda Crussius.

Por fim, vale dizer que o combate à burocratização dos serviços estatais e a democratização do acesso ${ }^{7}$ podem viabilizar um combate à crise estrutural do Estado de Bem Estar Social bem mais qualificado do que a proposta corrente de embate financeiro-financista que os "economistas" dos governos têm patrocinado nos últimos tempos.

A crise constitucional ou institucional parece conseqüência das outras crises. Se o modelo de Estado não funciona, inevitavelmente, a Constituição acaba tendo seu alcance reduzido, o que naturalmente fragiliza a democracia. Ademais, a fidelidade ao padrão liberal-burguês acaba por sufocar os dispositivos constitucionais que arrimam o welfare state, privilegiando as liberdades públicas em detrimento dos processos de igualização, indispensáveis, especialmente, aos países de modernidade tardia como o Brasil. O mercado, por sua vez, continua a influenciar o Estado e o Judiciário, reclamando das estruturas públicas - no que é atendido plenamente - a manutenção do status quo, que ampara a concentração de riqueza e o aumento da miserabilidade.

A crise política ou representacional firma-se na limitação da contribuição da democracia grega, que, na modernidade, acaba por constituir-se num paradigma simbólico. A evolução tecnológica e a complexidade das estruturas do Estado acabaram por reconhecer uma insuficiência da representação enquanto instrumento efetivo da democracia. Ao mesmo tempo, os processos de democracia direta estão assaz distantes de representar um grau de efetividade plausível.

Assim, o certo é que o sistema político não consegue acompanhar a evolução da sociedade, nem tampouco materializar a democratização das estruturas que foram erigidas pelo Estado Moderno. Se não bastasse, o mundo tem se revelado pouco prodigioso e criativo no tocante à criação de (efetivamente) novos modelos de governo. Foi deflagrado um processo de igualização perversa das propostas de governo, o que acaba por limitar a semântica da "escolha" do cidadão no exercício livre do sufrágio na democracia representativa. As eleições dos EUA e as recentes eleições argentinas, que reconduziram a família Kirchner ao poder, são exemplos dessa realidade, que se traduz num processo de desinteresse geral nos procedimentos eletivos e no que pode se denominar de despolitização coletiva ou relegação da política à matéria de interesse secundário.

\footnotetext{
${ }^{7}$ Idem, p. 151.
} 
Por fim, a crise funcional, que representa uma espécie de autofagia do Estado, já que um poder acaba por firmar sua sobrevivência à custa do outro ${ }^{8}$. A concepção de Montesquieu, efetivamente, registra problemas evidentes de aplicação. Parece, contudo, que tal fado arrima-se muito mais nos equívocos de gestão do que na constatação de falhas da Teoria do Estado. A confusão entre as tarefas designadas ao Executivo, Legislativo e Judiciário, hoje, é generalizada. A atuação do Judiciário enquanto poder discricionário, quando, avançando na legitimidade eletiva do Chefe do Executivo determina critérios de prioridade de gestão, redirecionando investimentos públicos, é um dos retratos dessa crise. A condução judiciosa e a tentativa de politização do jurídico protagonizada pela onda de CPIs que o Brasil tem vivenciado nos últimos anos é outro exemplo da aporia. Por fim, com o propósito de suscitar um fato bastante recente, cabe apontar a discussão orçamentária que tem sido protagonizada pelo Tribunal de Justiça e o Governo do Estado do Rio Grande do Sul, bem como o conflito do corte de salários, desta feita entre governo estadual e tribunal de contas.

Essa reflexão, parece, não deve levar à morte do Estado $^{9}$, mas sim a um redimensionamento de seu perfil. Ou seja, a solução passa, inexoravelmente, pelo Estado. "O Estado não está morrendo, mas passa por uma desregulação, seja quanto aos seus espaços abertos (em termos regionais), ou no plano de sua soberania." ${ }^{10}$

Acrescenta-se às crises elencadas a jurisdicional, que se põe como um tópico peculiar das crises do Estado Moderno ou como um subproduto da crise funcional e constitucional. Isso porque o Estado-juiz, diferentemente do Estado-Executivo, desde a clássica teoria de Montesquieu ${ }^{11}$, não traz dentre as suas características a tarefa de assegurar a execução de provimentos sociais imediatos, que atentam às demandas postas. A atividade judicante busca sim, além de solver os conflitos de ordem privada, assegurar a proteção dos interesses coletivos e difusos, mesmo que para isso seja necessário compelir o poder público à execução de obras e serviços, respeitado o princípio administrativo da discricionariedade e os limites da judicialização do político, tendo como balizes os princípios constitucionais implícitos da proporcionalidade e da razoabilidade.

\footnotetext{
${ }^{8}$ Idem, p. 156.

${ }^{9}$ Em que pese existam posições distintas, como a defendida por Federici, que afirma ser possível pensar na morte do Estado. Segundo ele, a falta de vontade política frente aos fenômenos apresentados pela globalização, a perda da exclusividade funcional e da soberania fomentam a sua fragmentação e diluição. Porém, Federici pondera que o Estado de morrer para viver, ou seja, seu passamento representa a necessidade de uma transformação profunda, que absorva os elementos históricos distantes do Estado na modernidade. (FEDERICI, Mario. Las Transformaciones Finiseculares del Estado. Foro Político. Revista Del Instituto de Ciências Políticas. Cátedra Ortega. Universidade del Museo Social Argentino. Volumen XXVIII, abril, 2000. p. 100.)

${ }^{10}$ SPENGLER, Fabiana Marion. Crise Funcional: Morte ou Transformação do Estado? In: MORAIS, José Luis Bolzan (Org.). O Estado e suas Crises. Porto Alegre: Livraria do Advogado, 2005. p. 139-40.

${ }_{11}$ MONTESQUIEU. O Espírito das Leis. Traduzido por Luiz Fernando de Abreu Rodrigues. Textos selecionados. Curitiba: Juruá, 2001.
} 
Dessa forma, pode-se dizer que o ato jurisdicional não traz em si a solução para o conflito, mas apenas a determinação que, quando executada, face à legitimidade da decisão, produza-se efeitos no sentido de assegurar a paz social, cujo alicerce encontra clareza já no pensamento de Rosseau. ${ }^{12}$

É cediço que o Direito Romano calcava-se na tutela dos interesses individuais, uma vez que a idéia de "interesses coletivos" não permeava o processo civil tradicional. Assim, embora o poder público já admitisse os "direitos coletivos" enquanto dever, organizando-se nesse sentido, o EstadoJuiz não registrava essa concepção, efetuando, assim, uma jurisdição privada. Ovídio Baptista da Silva critica um dos reflexos dessa influência:

O singular fenômeno que acabou plasmando o direito moderno da tradição romano-canônica foi conseqüência do trabalho dos compiladores medievais, que acrescentaram às duas formas de obrigação - o delito e o contrato - as ditas 'obrigações legais', sob a consideração de que nos tornamos obrigados não apenas pelo contrato ou pelo delito, mas também pela lei. Ora, se qualquer norma jurídica impõe-nos uma obrigação, a desobediência a qualquer delas resultará em condenação. Manteve-se, assim, exageradamente ampliada a estrutura do procedimento privado da actio romana: a toda obrigação corresponderá uma condenação, o que decorrerá sempre que alguma disposição legal seja violada, posto que a lei impõe-nos uma 'obrigação'.13

A exegese, que prevê uma interpretação gramatical da lei, com rígidos limites de emprego, e que ainda norteia a jurisdição contemporânea, próxima do Estado liberal-privatista, põe-se na contramão da prestação jurisdicional pública, realizadora dos Direitos Fundamentais e asseguradora da inclusão social.

Mas certamente que o principal motivador da crise jurisdicional não é a compreensão limitada da actio romana, bem como da dogmática processual tradicional, mas sim a ausência de um perfil democrático na atividade judicante, o que acaba retirando a legitimidade social e ética do procedimento, precipuamente pela inefetividade do ius facere, ou seja, a morosidade ou mesmo a não realização dos provimentos oriundos do comando sentencial. Essa, a gênese da chamada crise de autoridade do ato decisional. Como aponta Ovídio Baptista da Silva:

Nossa submissão à actio romana e ao correspondente procedimento ordinário, fundamentalmente um reflexo do privatismo a que ficou reduzida a jurisdição, transformada em assunto entre credores e devedores, impede o resgate da categoria dos deveres, cuja recuperação se mostra tão urgente em nosso sistema que, apesar da cultura privatística, ainda apresenta traços saudáveis de sua vocação para o direito público,

\footnotetext{
${ }^{12}$ ROSSEAU, Jean Jacques. O Contrato Social. Traduzido por Antonio de Pádua Danesi. 3. ed. São Paulo: Martins Fontes, 1996.

${ }^{13}$ BAPTISTA DA SILVA, Ovídio Araújo. Processo e Ideologia: O Paradigma Racionalista. p.133.
} 
Dessa forma, ingente a publicização da jurisdição, rompendo-se com o individualismo, que, fruto do caráter liberal do direito, deita suas garras na modernidade, constituindo-se numa de suas principais características.

Assim, faz-se necessária a construção de uma jurisdição democrática que supere as características formalistas, as quais percebem, no mais das vezes, o fundamento procedimental como razão suficiente ao afastamento do exercício jurisdicional pleno, que se aproxima do mundo da vida, desconsiderando-se 0 alcance material, real escopo do Estado, realizador do direito. ${ }^{15}$

E o Estado Moderno, na busca de identidade, ainda não implementou um modelo democrático que assegure a inclusão, seja no que toca à razão de fundamento, seja em relação à adequada gestão do tempo, fundamental para a materialização de uma jurisdição digna.

É necessário, nesse sentido, buscar uma alternativa aos libertários, cujo prestígio do mercado revela-se absolutamente excessivo, aos liberais contratualistas, que trazem a concepção kantiana de asseguração dos direitos civis e aos comunitaristas, que valorizam a multiplicidade de identidades presentes na sociedade. ${ }^{16}$

Parece que essa proposta, que aponta uma nova senda democrática, deve perceber a linguagem e a intersubjetividade como esteios da jurisdição democrática. Ao reconhecer a presença inquestionável dos liberais, na diversidade de percepções individuais e dos comunitaristas, no reconhecimento das diferentes formas de composição da sociedade, a consideração adequada da Constituição e a percepção adequada do tempo surgem como alternativa ao combate da (in) efetividade das políticas estatais e, também, da jurisdição.

Mas essa compreensão de Estado, essa busca da identidade, não é por si só, suficiente à democratização da jurisdição, uma vez que encontra o ser, mas não lhe assegura mobilidade, nem tampouco define o alcance necessário desse processo de (re) democratização jurisdicional.

Nesse talante, o juiz não está subordinado à exigência inexeqüível que Ihe faz o sistema, de forma a extrair da lei o seu sentido unívoco. A idéia racionalista da sentença como ato meramente intelectivo da lei no qual o juiz

\footnotetext{
${ }^{14}$ Idem, p. 200.

${ }^{15}$ Como referenda Ovídio Baptista da Silva, quando aborda a crise paradigmática da academia e a submissão inarredável do direito ao poder, em que pese as tentativas de limitação da Constituição: "Enquanto pensarmos o Direito como uma questão lógica, capaz de ser resolvida como qualquer problema matemático; enquanto não perdermos a ilusão de que a lei - fruto, como o sistema pressupõe, de um legislador iluminado - tenha univocidade de sentido, a Universidade conservar-se-á imutável em sua metodologia jurídica, fornecendo ao sistema contingentes de servidores, aptos para a tarefa de descobrir a inefável "vontade da lei", a que se referia Chiovenda e que, para nosso tempo, confunde-se com a "vontade do poder". Idem, p. 53.

${ }^{16}$ Idem.
} 
não interpreta o texto, mas apenas extrai dele seu puro sentido literal merece ser afastada dando azo a uma nova concepção de sentença como ato de vontade - não da lei, que é ser inanimado - através do qual o juiz alcança ao texto legal um caráter de legitimidade jurídica e social, operando volitivamente - mas democrática e constitucionalmente - na tarefa de intelecção do texto legal.

Como assevera Ovídio Baptista da Silva, ao criticar o atual critério sucumbencial do processo:

O verdadeiro custo do processo, representado pelo tempo, não onera jamais o demandado que, durante o interminável procedimento ordinário, tem o privilégio de desfrutar do statu quo ante, sem responder pelo custo representado pelo tempo. ${ }^{17}$

De fato, assiste razão ao magistério de Ovídio, na medida em que o tempo do processo envolve uma dimensão distante da realidade, mormente em razão do nítido favorecimento do demandado, que pode utilizar dos artifícios processuais para alcançar privilégios materiais no feito. A execução, quiçá, seja o principal exemplo de tal reflexo, na qual o devedor é erigido à categoria de hipossuficiente exacerbado, dificultando sobremaneira a busca da satisfação do crédito.

Nesse cenário que a crise jurisdicional pode receber importante contribuição visando sua superação. O rompimento com a ótica privatistaliberal, mediante a confecção de um modelo de jurisdição democrática, com o alcance de uma legitimidade social, que contemple a multiplicidade de elementos que compõe a sociedade, redundaria numa efetiva inclusão, contemplando, inclusive, os ditos elementos marginais, que, embora não recebam a tutela legal do Estado, podem, a partir de um exercício de interpretação adequado, alcançar a condição de sujeito de direitos, na esteira da teoria constitucional.

\section{A MATRIZ ESTATAL CONTEMPORÂNEA E O COMPROMISSO RACIONALISTA DO PROCESSO}

O Estado Moderno, como dito alhures, enfrenta uma crise de identidade, que encontra diversas matrizes. A crise é fruto da insuficiência conceitual que o Estado revela diante das pretensões que registra, especialmente em face do mosaico de sustentação que foi angariando ao longo da história.

Ovídio Baptista da Silva aponta para um antagonismo entre a liberdade - pretendida pelo liberalismo - e a igualdade ${ }^{18}$, cujos valores não poderiam

\footnotetext{
${ }^{17}$ Idem, p. 212.

${ }^{18}$ Nessa linha, as altercações do Autor: Os liberais não apenas dão prioridade à liberdade; eles se opõem à igualdade, pois se opõem vigorosamente a qualquer conceito medido em função de resultado, única maneira de dar sentido ao conceito de igualdade. Na medida em que liberalismo é a defesa do governo racional, baseado no julgamento informado dos mais competentes, a igualdade se lhe apresenta como um conceito nivelador, antiintelectual e inevitavelmente extremista; para concluir: "O próprio termo "liberal" incorpora não só o significado político mas a prática da
} 
ser alcançados num sistema progressivamente excludente, como tem se revelado o liberal. Ademais, sinala a herança racionalista como um dos precípuos empeços do aprimoramento da eficácia das funções do Estado e da efetividade jurisdicional. Baptista da Silva efetua construção interessante no sentido de coadunar o exame do racionalismo moderno com a democracia, que teria privilegiado a justiça comutativa aristotélica, abandonando seu caráter distributivo, o que funda, também, o escopo liberal. A esse teor, suas afirmações:

O direito racional moderno, por exemplo, privilegiou apenas uma das formas de justiça preconizada por Aristóteles, legitimando somente a 'justiça comutativa', conciliando-se, ao contrário, precariamente com os princípios da 'justiça distributiva' que, como é natural, antes de ter por fim a conservação do statu quo, deve lutar para transformá-lo. A justiça distributiva representa o componente revolucionário do Direito. Conseqüentemente, não seria de esperar que o novo ordenamento jurídico concebido, acima de tudo, com sistema de segurança legal, pudesse priorizar esta forma revolucionária de justiça. ${ }^{19}$

Ademais, o direito ainda enfrenta o paradigma absolutista de que a lei é o depositário de todas as esperanças do Estado e do indivíduo, bem como o sustentáculo que a Ciência Jurídica oferece ao aparato estatal. Logicamente que esse caráter positivista ortodoxo e pernicioso acaba por influenciar o perfil do Estado, que se inclina para uma identidade fulcrada no exercício objetivo e lógico da norma, em descompasso com uma sociedade cada vez mais complexa.

O Estado, assim, firmado no positivismo, acaba por ofertar espeque à proposta liberal de manutenção do status quo, vez que o rompimento paradigmático através da alteração da legislação revela-se muito mais árduo do que aquele buscado pela autoridade da jurisdição e pelo precedente, características típicas do common law. Nessa esteira, o pensamento ovidiano:

Não somos capazes de compreender seu verdadeiro núcleo, porque estamos cegos pelo dogma positivista de que todo o direito encerra-se na lei, conseqüentemente supervalorizamos a importância da lei no processo de conhecimento jurídico... O que está, como ideologia, por traz do monopólio da lei (absolutismo legal) não é outra coisa senão a idéia do Estado de Direito, do modo como ele foi concebido no século XIX e que entre nós ainda está viva, embora às vezes violada. Este Estado de Direito é, em sua essência, um Estado Legal. É o Estado em que somente a lei está convocada a garantir a justiça, a liberdade e a segurança. Conseqüentemente, a produção do direito é atribuída apenas ao legislador, não aos outros poderes

largueza, do noblese oblige. Indivíduos poderosos podem ser liberais em sua distribuição dos valores materiais e sociais. $E$ vemos aqui, muito abertamente, o vínculo existente com o conceito de aristrocacia, ao qual o liberalismo pretende se opor." Idem, p. 312.

${ }^{19}$ Idem, p. 68. 
públicos ou à pessoa individual. A teoria da separação de poderes é interpretada no Estado legislativo como a reserva, para esse poder, da atividade criadora do direito. O 'poder' judiciário está limitado a 'aplicar' o direito criado pelo legislador [...]. Consequentemente, segue-se desta premissa que todos os critérios e considerações para o Estado de Direito e uma violação do princípio de separação de poderes. ${ }^{20}$

Assim, com o propósito de viabilizar a jurisdição participativa, que supere a concepção formalista-privatista - que insiste em tutelar um processo ortodoxo que não se adapta à recepção dos direitos difusos-coletivos, faz-se necessário arquitetar uma concepção crítica da linguagem e ir um pouco além das matrizes teóricas estatais desenvolvidas na modernidade. Hoje, lançando mão da linguagem empregada na ciência política, pode-se dividir a representatividade ideológica-estatal em três correntes largamente difundidas e uma quarta, ainda precoce.

A primeira, representada principalmente pelas idéias de Robert Nozic e Friedrich Hayek ${ }^{21}$, para quem o aparato coercitivo do Estado Moderno tem sido utilizado com o fim de ultrajar o indivíduo e violar seus direitos, tecendo duras críticas à teoria da solidariedade social, pode ser denominada de corrente libertária e possui conotação eminentemente privatista.

A segunda, que tem como expoentes John Rawls ${ }^{22}$ e Ronald Dworkin ${ }^{23}$, nominada de liberal contratualista, de vertente kantiana, sustenta a sociedade numa concepção de preservação das identidades, reconhecendo como natural o surgimento de conflitos, que, contudo, devem ter como norte às concepções individuais dos membros da sociedade, rechaçando a luta de classes e a organização da sociedade civil em entidades e grupos. ${ }^{24}$

Os comunitaristas, por sua vez, recuperam a retórica aristotélica, muito bem interpretada por Perelman, em sua obra clássica, "Tratado da argumentação". ${ }^{25}$

Perelman sustenta que a teoria da argumentação não se pode desenvolver quando toda visão é concebida como redução à evidência e situa seu objeto

${ }^{20}$ Idem, p. 270.

${ }^{21}$ HAYEK, Friedrich A. von. O Caminho da Servidão. Tradutores/Revisores: Anna Maria Capovilla; José Italo Stelle; Liane De Morais Ribeiro. Rio de Janeiro: Instituto Liberal, 1984.

22 RAWLS, John. Uma Teoria da Justiça. Traduzido por Almiro Pisetta; Lenita Maria Rímoli Esteves. 2. ed. São Paulo: Martins Fontes, 2002.

Libertad, Igualdad y Derecho: Las Conferencias Tanner sobre Filosofia Moral. 1. ed. Barcelona: Ariel, 1988.

${ }^{23}$ DWORKIN, Ronald. Uma Questão de Princípio. Traduzido por Luís Carlos Borges. São Paulo: Martins Fontes, 2001 O Império do Direito. Traduzido por Jefferson Luiz Camargo. São Paulo: Martins Fontes, 1999. . Los Derechos en Serio. Traduzido por Marta Guastavino.

Barcelona: Ariel, 1984.

${ }^{24}$ CITTADINO, Gisele. Pluralismo, Direito e Justiça Distributiva. Elementos da Filosofia Constitucional Contemporânea. 2 ed. Rio de Janeiro: Lúmen Júris, 2000.

${ }^{25}$ PERELMAN, Chaïm; OLBRECHTS-TYTECA, Lucie. Tratando da Argumentação. Traduzido por Maria Ermantina Galvão G. Pereira. São Paulo: Martins Fontes. 1996. 
no "estudo das técnicas discursivas que permitem provocar ou aumentar a adesão dos espíritos às teses que se lhe apresentam ao assentimento" ${ }^{26}$

Idade Média trabalhou com a ciência da criação, da diversidade, emanada de Aristóteles ${ }^{27}$, enquanto que a modernidade trouxe à tona Platão ${ }^{28}$, defendendo a ciência da descoberta, da certeza e da exatidão. Na linha da teoria platônica, o Direito enquanto produtor de diferenças de ciência que repugna as verdades absolutas, já que trabalha com versões e não concepção definitivas, sofreu um forte ultraje, passando por um período de igualização perversa em relação às demais ciências.

A modernidade trouxe de volta a idéia de Aristóteles e devolveu ao Direito a retórica, percebendo-o como um processo de construção permanente e revisão dos paradigmas positivistas estabelecidos.

Os comunitaristas, que ofertam abrigo ao pensamento de Michael Walzer ${ }^{29}$, Charles Taylor $^{30}$, Michael Sandel ${ }^{31}$ e Alasdair Maclntyre ${ }^{32}$, põe-se nessa linha' de raciocínio, já que valorizam a multiplicidade de identidades sociais e o pluralismo cultural, percebendo a sociedade através dos agrupamentos e não por meio de um enfoque individualista. Daí ressai a crítica aos liberais, que, segundo os comunitaristas, não sabem lidar com as situações intersubjetivas, pois produzem, na expressão de Cittadino, uma "sucessão alternada de monólogos". 33

Por fim, os críticos-deliberativos, partidários da teoria da ação comunicativa de Jürgen Habermas, que vislumbra uma fusão das teorias políticas na modernidade, a qual se funda na variedade dos signos e no pluralismo de idéias, que encontram terreno fértil na diversidade cultural.

No dizer de Gisele Cittadino, para os crítico-deliberativos:

(a) os valores normativos modernos só podem ser compreendidos por meio de leituras intersubjetivas, (b) o princípio do universalismo moral foi encarnado de modo imperfeito nas instituições do Estado constitucional, tendo definhado a ponto de não ser mais do que uma simples palavra, (c) só a razão comunicativa possibilita "acordos sem constrangimentos" em condições de se irradiar para toda a sociedade,

\footnotetext{
${ }^{26}$ Idem, p. 4.

${ }^{27}$ DURANT, Will. A História da Filosofia. Rio de Janeiro: Nova Cultural, 1999.

28 PLATÃO. PLATÃO. Crátilo. Diálogo sobre a Justeza dos Nomes. Traduzido por Pe. Dias Palmeira. 2. Ed. Lisboa: Sá da Costa Editora, 1994.

${ }^{29}$ WALZER, Michael. Das Obrigações Políticas: Ensaios sobre Desobediência, Guerra e Cidadania. Traduzido por Helena Maria Camacho Martins Pereira. Rio de Janeiro: Zahar, 1977.

${ }^{30}$ TAYLOR, Charles. El Multiculturalismo y la Política del Reconocimiento. Traduzido por Mônica Utrilla de Neira. México: Fondo de Cultura Econômica, 1993.

${ }^{31}$ SANDEL, Michael. Democracys Discontent. América in Search of a Public Philosophy. Cambridge: Harvard University Press, 1996.

${ }^{32}$ MACINTYRE, Alasdair. A Short History of Ethics: A History of Moral Philosophy from the Homeric age to the Twentieth Century. 2. ed. London: Routledge, 1998.

${ }^{33}$ CITTADINO, Gisele. Pluralismo, Direito e Justiça Distribuitiva. Elementos da Filosofia Constitucional Contemporânea. 2 ed. Rio de Janeiro: Lúmen Júris, 2000. p. 35.
} 
e (d) a diversidade das concepções individuais a respeito da vida digna, apregoada pelos liberais, e a multiplicidade de formas específicas de vida que compartilham valores, costumes e tradições enfatizadas pelos comunitaristas, estão presentes nas democracias contemporâneas, não havendo como optar por uma em detrimento da outra. ${ }^{34}$

O certo é que a concepção política atual funde suas concepções, dificultando a definição do sistema jurídico de atuação consoante o sistema político, uma vez que o último se apresenta de forma bastante difusa, produzindo reflexos decisivos no primeiro.

Leonel Severo Rocha expõe a concepção habermasiana, quando sugere uma nova cultura política, também com a participação da teoria da Leford:

Uma nova cultura política permitiria pensar o espaço público enquanto topos de invenção política (Leford) e, simultaneamente, como uma matriz discursivo-programática disposta a aprofundar a proposta da Teoria da Ação Comunicativa (Habermas). Pois, neste último sentido, a cultura política se situaria entre a crítica da razão sistemático-semântica da modernidade e a crítica irracionalista da pós-modernidade à procura de uma racionalidade pragmático-quase-transcendental, ou seja, colocaria a democracia como princípio gerador transcendente e pragmático da práxis político-discursiva da instituição imaginária das sociedades. ${ }^{35}$

A Constituição, da forma como é posta, é o reflexo do sistema político vigente. Todavia, a sua concepção enquanto norte cultural inverteria essa lógica, atribuindo-lhe caráter de rigidez social, já que amparada no rol de valores da sociedade, evitando, assim, que ela fosse levada aos ventos das maiorias transitórias.

Os direitos de cidadania, comunicação e participação política, segundo a concepção republicana, são direitos positivos, que não garantem liberdade em relação à coação externa, mas sim a participação em que os cidadãos se tornem sujeitos politicamente responsáveis de uma comunidade de pessoas livres e iguais.

A sociedade política que os republicanos esboçam é a sociedade dos portadores de direitos privados, uma associação cujo primeiro principio é a proteção das vidas, liberdades e propriedades de seus membros individuais. Nessa sociedade o Estado é justificado pela compreensão que dá aos interesses pré-políticos. O propósito da Constituição é assegurar que o aparato estatal alcance proteção para o povo sem servir a interesses privados dos governantes. ${ }^{36}$

A força origina-se do poder gerado de forma comunicativa em meio a

\footnotetext{
${ }^{34}$ Idem.

${ }^{35}$ ROCHA, Leonel Severo. Espistemologia Jurídica e Democracia. São Leopoldo: Unisinos, 2003. p. 175.

${ }^{36}$ CITTADINO, Gisele. Pluralismo, Direito e Justiça Distribuitiva. Elementos da Filosofia Constitucional Contemporânea. 2. ed. Rio de Janeiro: Lúmen Júris, 2000.
} 
práxis de autodeterminação dos cidadãos do Estado e legitima-se pelo fato de defender essa mesma prática através da institucionalização das liberdades públicas.

Fala-se em processo inclusivo que não chegue à conclusão de que todos têm os mesmos direitos, mas sim a um consenso, cujo pressuposto de legitimidade é a asseguração da participação social. No que tange ao conceito da pessoa de direito, percebe-se um cunho subjetivo na teoria liberal e uma predominância da garantia da integridade, através de uma perspectiva objetiva. O direito ao voto, por exemplo, é uma liberdade positiva, por ser constitutivo para a autodeterminação política e a associação ao direito individual no sentido de garantir posicionamentos próprios dos participantes do processo político.

A natureza do processo político, segundo a concepção liberal, representa uma luta por posições em busca do poder administrativo, onde predomina o caráter estratégico. O êxito é medido pela concordância dos cidadãos acerca dos projetos e programas. Esses eleitores licenciam o poder dos governantes. Os republicanos defendem a formação de opinião não como um mero reflexo das leis de mercado, mas como uma interlocução entre os agentes políticos e a sociedade organizada, através da comunicação discursiva.

O discurso político apresenta força vinculativa, encontrando limites nas leis que nascem através do processo democrático e instrumentos que recaem sobre as políticas públicas. O caminho para a jurisdição democrática, contudo, não é um discurso racionalizador que exclua ações estratégicas, já que os acordos pressupõem uma questão de justiça e não de ética, que não estão relacionadas, desde a origem, a uma coletividade em particular.

Assim, a partir da intersubjetividade e da autodeterminação dos cidadãos, busca-se fundamentar uma práxis democrática que viabilize a gestão de espaços públicos entre o Estado e Sociedade Civil $^{37}$, visando a interlocução

\footnotetext{
${ }^{37}$ No Caderno 8, escrito em 1932, Gramsci tece algumas observações que denotam um pouco as angústias do Estado da época, bem como as pretensões dos que pensavam serem protagonistas de uma fase de transição, o que, por sinal, remete à modernidade, que também avoca para si tal característica temporal, ao menos no que toca ao Direito, especialmente o Direito Constitucional. Como aduz Gramsci ao considerar o espectro político de 32: "A geração atual tem uma estranha forma de autoconsciência e exerce sobre si uma estranha forma de autocrítica. Tem a consciência de ser uma geração de transição ou, melhor ainda, acredita ser como uma mulher grávida: acredita estar por dar à luz e espera nascer um grande filho. Muitas vezes se lê que "estamos na expectativa de um Cristóvão Colombo, que descobrirá uma nova América da arte, da civilização, do costume". Também se lê que vivemos numa época préDante: espera-se o novo Dante que sintetize poderosamente o velho e o novo e dê ao novo o impulso vital. Este modo de pensar, recorrendo a imagens míticas tomadas do desenvolvimento histórico passado, é dos mais curiosos e interessantes para compreender o presente, seu vazio, sua ociosidade intelectual e moral. Trata-se de uma forma de "juízo retrospectivo" das mais espantosas. Na realidade, com todas as profissões de fé espiritualistas e voluntaristas, historicistas e dialéticas, etc., o pensamento que domina é o evolucionista vulgar, fatalista, positivista. Seria possível formular assim a questão: toda "glande" pode pensar em se tornar carvalho. Se as glandes tivessem uma ideologia, esta seria justamente a de se sentirem "grávidas" de carvalhos. Mas, na realdade, de cada mil glandes, 999 servem de pasto aos porcos e, no máximo, contribuem
} 
dos autores e a confecção de políticas públicas dotadas de efetividade e eficácia social.

Entretanto, a jurisdição afasta-se dessa necessária prática democrática. Produto anacrônico de uma distorcida concepção, a jurisdição perde-se na tentativa de cumprir o inatingível papel que Ihe confere a História. Legatária do jusracionalismo, a jurisdição ainda busca fórmulas de precisão, como se a Ciência do Direito pudesse amoldar-se a tais paradigmas. Ao referir o modo de produção do conhecimento filosófico no Século XVII, Cassirer reconhece que se tratou essencialmente da busca da certeza que pudesse ser logicamente demonstrável, numa precisão absoluta. Depois de referir que a tarefa que se apresentava era a de criar uma conexão a partir de uma certeza absoluta, Cassirer reconhece a necessidade de percorrer-se uma "cadeia do cognoscível",38 e que "nenhum elo dessa cadeia pode ser separado do conjunto, nenhum deles se explica nem se conclui por si mesmo". ${ }^{39}$

O mesmo efeito verificou-se na ciência do Direito. Reconhecendo essa circunstância, Engisch fixa no tempo a rigorosa vinculação do juiz à lei, quando afirma:

Houve um tempo em que tranqüilamente se assentou a idéia de que deveria ser possível estabelecer uma clareza e segurança jurídicas absolutas através de normas rigorosamente elaboradas, e especialmente garantir uma absoluta univocidade a todas as decisões judiciais e a todos os atos administrativos. ${ }^{40}$

O apego às formas do jusracionalismo faz do direito uma ciência que enfrenta um paradoxo constante. De um lado, a espera da segurança jurídica absoluta, o anseio pela uniformidade das decisões judiciais e a sistematização de seus códigos e instrumentos. De outro, a expectativa do mundo contemporâneo, tão diferente daquele do século passado.

O paradigma racionalista, dessa forma, representa um compromisso científico com a exatidão e com o rigor lógico: somente a partir de uma racionalidade o direito natural encontrava sustentação, exatamente quando procurava distinguir-se do absolutismo. O movimento de afirmação do antropocentrismo precisou firmar-se em bases que permitissem a sua oposição ao teocentrismo. Decorre daí, então, a sedução pela lógica, que possibilitava a universalidade do direito e justificava o jusracionalismo.

A par da exatidão, também constituem marcas do racionalismo a exaltação da segurança jurídica, mencionada anteriormente, e a aparente neutralidade

para criar chouriços e mortadelas." (GRAMSCI, Antonio. Cadernos do Cárcere. Rio de Janeiro: Civilização Brasileira, 1999-2002. p.122-3.)

${ }^{38}$ CASSIRER, Ernst. A Filosofia do lluminismo. Traduzido por Álvaro Cabral. Campinas: Unicamp. 1992. p. 24.

${ }^{39}$ Idem, p. 24

${ }^{40}$ ENGISCH, Karl. Introdução ao Pensamento Jurídico. Traduzido por J. Baptista Machado. 7. ed. Lisboa: Fundação Calouste Gulbenkian, 1996. p. 206. 
do julgador, esta conferida pela sustentação do dogma da univocidade da norma jurídica. Como aponta Ovídio Baptista da Silva:

O abandono da ilusão de que o raciocínio jurídico alcance a univocidade do pensamento matemático, não nos fará reféns das arbitrariedades temidas pelo pensamento conservador, porquanto não se deve confundir discricionariedade com arbitrariedade. O juiz terá - na verdade sempre teve e continuará tendo, queiramos ou não -, uma margem de discrição dentro de cujos limites, porém, ele permanecerá sujeito aos princípios da razoabilidade, sem que o campo da juridicidade seja ultrapassado. ${ }^{41}$

O espectro epistemológico da Ciência Jurídica, portanto, está vinculado a esse paradigma da precisão, que se afasta da compreensão, informada pelo razoável e pelo plausível, consolidando a idéia de univocidade do sentido da norma.

Para a materialização desse desiderato, o direito lança mão das formulações lógicas, comprometidas com princípios metafísicos e que ainda reverenciam a atemporalidade e a supra-espacialidade, propósitos típicos de uma postura que procurou conferir validade universal à Ciência Jurídica, conseqüência da necessidade de afirmação do antropocentrismo.

Quando se afirma a univocidade do sentido da norma, sob a justificativa de que é necessário conferir neutralidade à atuação da jurisdição, retira-se do julgador a possibilidade de crítica. Retira-se a responsabilidade da jurisdição que é transferida para quem elabora a norma. A norma é que é justa ou injusta, não a sua aplicação ao caso concreto. Então, a missão da jurisdição não encontra relação com a realização da justiça, na medida em que se trata, apenas, de aplicar a norma.

Esses objetivos também são alcançados pela segurança jurídica, afastando-se a materialização da justiça e a efetividade jurisdicional. Como sinala Ovídio Baptista da Silva:

A criação do 'mundo jurídico', tão presente em nossas concepções do Direito, foi uma conseqüência inevitável do racionalismo. Não é de estranhar que nossas Universidades limitem-se a ensinar essas 'verdades eternas' que prescindem dos fatos. O direito processual moderno, como disciplina abstrata, que não depende da experiência, mas de definições, integra o paradigma que nos mantém presos ao racionalismo, especialmente ao lluminismo, que a História encarregou-se de sepultar. Esta é a herança que temos de exorcizar, se quisermos libertar de seu jugo o Direito Processual Civil, tornando-o instrumento a serviço de uma autêntica democracia. É ela a responsável pela suposta neutralidade dos juristas e de sua ciência, que, por isso, acabam permeáveis às

${ }^{41}$ BAPTISTA DA SILVA, Ovídio Araújo. Processo e Ideologia: O Paradigma Racionalista. p. 271. 
ideologias dominantes, sustentáculos do sistema, a que eles servem, convencidos de estarem a fazer ciência pura. ${ }^{42}$

É a partir da aceitação de que o direito não obedece a critérios lógicos, que é uma ciência da compreensão e, também, do reconhecimento da necessidade de afastar-se dos aspectos metafísicos que informam o método adotado pelas ciências jurídicas que se poderá estabelecer um novo paradigma.

Para romper com essa idéia de formalismo jurídico, é necessário reconhecer que o discurso jurídico está firmado em axiomas estabelecidos a partir dos conceitos admitidos como válidos, aceitando-se que a verdade obtenível é sempre relativa. Certamente que o pensamento dogmático é fruto da formação acadêmica dos juristas, porquanto tem como paradigma fundante a repetição sintomática que firma uma dependência epidêmica da lei, formando eternos alimentadores dessa vetusta prática alienada. Como afirma Ovídio Baptista: "'A aceitabilidade racional', expressa pelo verossímil no pensamento clássico, deve tomar o lugar da racionalidade linear da epistemologia das ciências empíricas". ${ }^{4}$

Além disso, o abandono da lógica tradicional, nas ciências do espírito, encontra justificativa também no fato de que o Direito se depara com a questão das noções lingüísticas, que são as representações gerais conferidas pelo filósofo da linguagem. Nesse sentido, Cassirer afirma que:

[...] a forma que conduz aos conceitos verbais primários e a determinadas denotações lingüísticas não é prescrita de modo simples e unívoco pelo próprio objeto, mas, ao contrário, abre um amplo campo de ação para a livre atividade da linguagem. ${ }^{44}$

Costuma-se diferenciar ciência jurídica da ciência do direito. A primeira, ciência jurídica designa "a ciência que trata do direito com os métodos especificamente chamados jurídicos" a "ciência do sentido objectivo do direito ou de qualquer 'ordem jurídica' positiva". ${ }^{46}$

Compreende-se por ciência do direito aquela que se ocupa do confronto do ordenamento com as questões que se apresentam ou, no dizer de Larenz, "aquela ciência que se confronta com a solução de questões jurídicas no contexto e com base em um ordenamento jurídico determinado". ${ }^{47}$

\footnotetext{
${ }^{42}$ Idem, p. 79.

43 Idem, p. 271.

${ }^{44}$ CASSIRER, Ernst. Linguagem e Mito. Traduzido por J. Guinsburg e Miriam Schnaiderman. 3. ed. São Paulo: Perspectiva, 1992b. p. 43.

${ }^{45}$ RADBRUCH, Gustav. Filosofia do Direito. Traduzido por L. Cabral de Moncada. 6. ed. ver. Coimbra: Armênio Amado, 1979. p. 227.

${ }^{46}$ Idem, p. 228.

${ }^{47}$ LARENZ, Karl. Metodologia da Ciência do Direito. Tradução da $6^{a}$ edição de José Lamego. 3. ed. Lisboa: Calouste Gulbenkian, 1997. p. 1.
} 
Ademais, a Ciência Jurídica não avança de modo igual às demais áreas do conhecimento científico, face às peculiaridades que lhe são imanentes.

Nesse trilho, pode-se recuperar a afirmação de Biondi, quando destaca que:

"formule e rigore sono fatte per le leggi di natura, che per postulato sono inflessibili e rigide, ma non per la realtà sociale che è così mutevole e varia da escludere ogni rigidità: il fenomeno giuridico è ben diverso dal fenomeno naturale." ${ }^{48} \mathrm{E}$, prosseguindo, indaga Biondi: "Dobbiamo forse percorrere a ritroso la storia della nostra scienza?". ${ }^{49}$

O direito não é uma ciência da descoberta ou da invenção. É, antes, uma ciência da especulação, uma ciência da compreensão. De qualquer maneira, mesmo sem imiscuir-se na discussão envolvendo o método apropriado às ciências da natureza, em relação às ciências do espírito, é preciso uma percepção diferente. Faz-se necessária uma abordagem que aceite 0 conteúdo essencial dessa ciência e, também, que trilhe caminho diverso da busca pela exatidão e certeza científicas, sob pena de permanecerem as amarras que empeçam a efetividade.

Ainda, a ciência jurídica distingue-se das outras ciências do espírito, porque, no âmbito jurídico, a interpretação encontra uma "palavra final" no próprio sistema, a partir da decisão judicial não passível de recurso. Essa qualidade não é encontrada em outras ciências sociais, onde a interpretação não é, ao final, "derrotada" pela definitiva decisão judicial.

A compreensão do método da Ciência Jurídica, assim, parece constituir-se num dos calcanhares de Aquiles do direito. A busca da exata compreensão de seu viés metodológico, assim, revela-se num dos passos necessários ao alcance da efetividade e da realização das pretensões materiais almejadas pelo direito. Nesse sentido, Hannah Arendt afirma que:

O mundo da experimentação científica sempre parece capaz de tornar-se uma realidade criada pelo homem; e isto, embora possa aumentar o poder humano de criar e de agir, até mesmo de criar um mundo, a um grau muito além do que qualquer época anterior ousou imaginar em sonho ou fantasia, torna, infelizmente, a aprisionar o homem - e agora com muito mais eficácia - na prisão de sua própria mente, nas limitações das configurações que ele mesmo criou. ${ }^{50}$

\footnotetext{
${ }^{48}$ BIONDI, Biondo. Universalità e Perennità della Giurisprudenza Romana. In: L'Europa e il Diritto Romano. Milano: Giuffrè, 1954. Vol. II. p. 399. "Fórmulas e rigor são feitos para as leis da natureza, que por essência são inflexíveis e rígidas, mas não para a realidade social que é assim mutável e varia excluindo a rigidez: o fenômeno jurídico é muito diferente do fenômeno natural."

${ }_{49}$ "Deveremos talvez retroceder na história da nossa ciência?" Idem, p. 400.

50 ARENDT, Hannah. A Condição Humana. Traduzido por Roberto Raposo. Rio de Janeiro: Forense-Universitária, 1987. p. 301.
} 
Todavia, o conhecimento científico é constituído a partir das condições e da evolução de um grupo, sendo o portador de características culturais, históricas, econômicas e sociais. Então, não pode ser considerado isoladamente, sem a percepção dessas condições. É por isso que Thomas Kuhn assevera "O conhecimento científico, como a linguagem, é intrinsecamente a propriedade comum de um grupo ou então não é nada. Para entendê-lo, precisamos conhecer as características essenciais dos grupos que o criam e o utilizam". ${ }^{51}$

O direito, assim, refoge da racionalidade matemática. Trata-se, apenas, de uma racionalidade diversa, peculiar da ciência jurídica, que é informada pela natureza da própria vida que gesta, em última análise, o fenômeno jurídico.

Nessa linha de raciocínio, desponta a importância dos momentos dialéticos, até mesmo intuitivos, para a Ciência Jurídica. Mais uma vez, o retorno à lógica do razoável, do provável e do verossímil.

Dispensar essa atenção ao direito, tratando-o a partir de uma concepção metafísica, significa tolher-lhe a possibilidade de cumprir seu papel e desenvolver-se plenamente como ciência, deixando de perceber a natureza que the é inerente. E, no dizer de Arthur Kaufmann ${ }^{52}$, irracional é fechar os olhos para os momentos peculiares do Direito, tão distantes da lógica formal, mas tão próximos da essência do Direito. O Direito deve compreender essa dimensão, sob pena de perder-se em si mesmo, incapaz que será de responder aos reclamos que se apresentam no mundo moderno.

O jusracionalismo representou a afirmação de um direito natural profano que se alforriou das amarras que mantinha com as concepções teológicas da Idade Média. Nesse ponto, importante a independência da doutrina religiosa. Essa "libertação" é descrita por Wieacker:

Se voltarmos à influência particular sobre a história do direito, são os traços metodológico-sistemáticos do jusracionalismo e a sua emancipação em relação à teologia moral que caracterizam o

${ }^{51}$ KUHN, Thomas S. A Estrutura das Revoluções Científicas. Traduzido por Beatriz Vianna Boeira e Nelson Boeira. 5. ed. São Paulo: Perspectiva, 1997.p. 257.

52 "É indiscutível haver também na ciência do direito e na filosofia do direito critérios de verossimilhança, de evidenciação, de falsificação e, assim, uma base para uma argumentação "razoável" bem como para um "consenso intersubjectivo". Daí fazer sentido, afinal, falar, também aqui, de "conhecimentos" e de "ciência". É claro que, nestes domínios, não existe uma "racionalidade" no sentido de exactidão matemática. No entanto, isto não quer dizer que aí se proceda "irracionalmente". Uma investigação também não é irracional por se ocupar de fenômenos que, pela sua parte, não são inteiramente racionais. Assim, a hermenêutica jurídica é uma ciência plenamente racional, se bem que - não: precisamente porque não trata o processo de determinação do direito como uma pura conclusão lógico-formal, mas como um processo muito mais complexo, que também compreende momentos produtivos, dialécticos, porventura até intuitivos. Irracional é fechar os olhos perante estes momentos. Uma ciência não pode, naturalmente, colocar-se em confronto com a lógica. Mas uma ciência que não se ocupa apenas do formal, tem de ir para além da pura lógica formal." (KAUFMANN, Arthur; HASSEMER, Winfried (Org.). Introdução à Filosofia do Direito e à Teoria do Direito Contemporâneas. Traduzido por Marcos Keel e Manuel Seca de Oliveira. Lisboa: Calouste Gulbenkian, 2002. p. 98.) 
jusnaturalismo moderno do continente europeu. Como teoria, ele liberta finalmente a jurisprudência técnica das autoridades da Idade Média e dá-Ihe um sistema interno e um método dogmático específicos - a construção a partir de conceitos gerais; como exigência prática fornece desde logo à crítica do direito, e depois à própria legislação um novo padrão moral. ${ }^{53}$

A partir disso, procurou-se desenvolver um método capaz de assegurar validade universal ao direito, mediante a afirmação da atemporalidade e da supra-espacialidade. ${ }^{54}$

Destarte, a aplicação da filosofia da linguagem ao Direito possibilita a adequação do provimento jurídico final aos anseios sociais, numa integração racional das figuras sociais (sociedade jurídica e sociedade civil). Perceber essa realidade e a partir da análise do modo de produção do Direito, dar azo à sedimentação de uma nova forma de compreensão da Ciência Jurídica e sua aplicação é o desafio que se apresenta, na busca da superação do racionalismo e na luta pela construção da cidadania.

\section{A PERNICIOSIDADE DA CERTEZA NO DIREITO}

O método tem papel determinante na definição do alcance que determinada ciência almeja. Nesse sentido, o abandono do racionalismo e da certeza enquanto instrumentos de determinação do norte da Ciência Jurídica traduz-se num passo fundamental.

Dessa forma, as ciências da natureza, dotadas de objetividade, de definitividade registram características diametralmente opostas às ciências do espírito. Impor a exatidão como critério metodológico às ciências do espírito, assim, é chancelar um processo de castração da criatividade humana.

As ciências do espírito, dentre as quais se coloca a do direito, operacionalizam-se a partir da compreensão, distantes da descoberta e da invenção, mas próximas da inventividade e da criação. O método do direito, portanto, é assaz distinto do empregado pelas ciências da natureza, que se ocupam com os fenômenos biológicos, químicos, físicos, astrológicos, geográficos e outros, de natureza análoga. O direito, infelizmente, tem experimentado a influência perniciosa do positivismo ortodoxo, que guarda

53 WIEACKER, Franz. História do Direito Privado Moderno. Traduzido por A. M. Botelho Hespanha. 2. ed. Lisboa: Calouste Gulbenkian, 1967. p. 306.

${ }^{54}$ Os juristas racionalistas procediam totalmente de acordo com a escolástica, na medida em que também eles estavam convencidos da possibilidade de, a partir de um reduzido número de princípios superiores apriorísticos, extrair, através da pura dedução, todas as restantes regras de direito, sem ter em conta a realidade empírica, as circunstâncias espaciais e temporais (pois só assim se acreditava poder-se assegurar ao direito natural a validade universal, para todos os tempos e para todos os homens). Na realidade, acabava por se proceder empiricamente, quando se pediam "empréstimos" ao direito romano, cuja racionalidade se enaltecia (era o tempo da recepção). Só assim puderam nascer os grandes códigos jusnaturalistas. (KAUFMANN, Arthur; HASSEMER, Winfried (Org.). Introdução à Filosofia do Direito e à Teoria do Direito Contemporâneas. p. 93.) 
características de racionalidade, buscando na certeza sua redenção, sem perceber que caminha para sua sepultura enquanto ciência autônoma.

O saber dogmático, assim, determina um proceder onde o culto pelo procedimento e pela forma ganha relevo, produzindo uma postura acrítica e não investigativa. Nessa linha, o pensamento de Ovídio Baptista da Silva, manifestado no embrião da obra "Processo e Ideologia":

A redução do conceito de ciência, peculiar ao pensamento moderno, que somente concebe como científicos os ramos do conhecimento humano destinados a medir, pensar e contar, fez com que o Direito se transformasse num conjunto sistemático de conceitos, com pretensão à eternidade, desvinculando-o da História. [...] O Direito Processual Civil foi o domínio jurídico mais danificado por essa metodologia, em virtude de ser o processo aquele ramo do conhecimento jurídico mais próximo do mundo da vida, da prática social e que, além disso, pressupõe que o acesso a seus domínios seja alcançado através da hermenêutica, naturalmente incompatível com o pensamento dogmático. ${ }^{55}$

A busca da univocidade do sentido da lei ultraja a compreensão hermenêutica do direito e reduz a jurisdição à funcionalidade declaratória. Como refere Ovídio Baptista da Silva, "o racionalismo, especialmente nos sistemas jurídicos herdeiros da tradição romano-canônica, tornou a tarefa judicial conceitualmente limitada a descobrir e verbalizar a "vontade da lei". ${ }^{56}$

A pretensão de validade universal do direito, firmada na idéia de neutralidade do julgador, também se agrega com o propósito de firmação da segurança jurídica, típico do racionalismo. Para Hernández Gil, o paradigma racionalista que se incorporou ao direito produziu o sacrifício do caráter individual das regras e do próprio ideal do direito. Sustentou, dessa forma, o triunfo da certeza que terminou por estereotipar o direito. ${ }^{57} \mathrm{~A}$ realização da justiça deixou de integrar as pretensões da Ciência Jurídica, sufocada pelo racionalismo. O papel da teoria crítica do direito é exatamente resgatar o viés interpretativo, recuperar a idéia do direito enquanto instrumento de realização da justiça.

A pretensão da codificação, proposta por muito tempo por Savigny, é fruto do caráter positivista ortodoxo, legalista, que propõe o direito como normatizador definitivo, com capacidade de abarcar todos os fatos apresentados ao julgador.

\footnotetext{
55 BAPTISTA DA SILVA, Ovídio Araújo. Processo e Ideologia: O Paradigma Racionalista. p. 1.

${ }^{56}$ Idem, p. 269.

${ }^{57}$ Antônio Hernández Gil afirma que "el conocimiento del Derecho pasó de la doxa (el practicismo no importa que erudito de los glosadores y exegetas) y de la filosofia (el Derecho natural racionalista) a la ciencia. Estos dos grandes sacrificados ante la ciencia - las reglas en su individualidad y el ideal del Derecho - no han dejado de formular protestas y reivindicaciones, que algunas vezes se han convertido en incompatibles, pero es lo cierto que la ciencia jurídica quedó estereotipada, como hemos dicho, a imagen de la naturaleza y de la lógica." (GIL, Antonio Hernández. Problemas Epistemológicos de la Ciencia Jurídica. 2. ed. Madrid: Civitas, 1981. p. 23).
} 
Nos dizeres de Ovídio Baptista da Silva, "é interessante observar como o predomínio da segurança sobre os ideais de justiça que, na Europa continental, deu ensejo à era das codificações, foi igualmente uma constante na doutrina jurídica inglesa". 58

A codificação representou a materialização dos propósitos de alcance da certeza e da segurança que fluíam através da lei, escapando do subjetivismo do julgador. A incorporação de métodos de raciocínio e dedução lógicos, a completa absorção do espírito científico peculiar daquele momento histórico, conduziram os rumos da ciência jurídica. A propósito, Wieacker elege como a mais importante contribuição do jusracionalismo para o Direito Privado europeu o seu sistema, afirmando que:

Para o jusracionalismo, desde Hobbes e Pufendorf, a demonstração lógica de um sistema fechado tornou-se, em contrapartida, na pedra de toque da plausibilidade dos seus axiomas metodológicos. Quando, no século XVIII, ele começou também a ordenar as exposições do direito positivo, facultou-lhes o sistema; aquele sistema que ainda hoje domina os códigos e os manuais. ${ }^{59}$

Essa codificação também se encontra impregnada pela ideologia racionalista-liberal podendo-se dizer, inclusive, que o próprio processo de instrumentalização generalizada do direito é fruto do processo ideológico que o domina. Segundo as afirmações de Tarello "no obstante el valor unívoco que la reflexión del siglo XIX ha dado al código, no es una ideología, sino que es la confluencia de diversos y discrepantes complejos ideológicos, que vemos presidir la gestación de los derechos codificados". 60

\section{CONSIDERAÇÕES FINAIS}

Os códigos, em regra, encontram-se comprometidos com posições conservadoras; entretanto, não há como deixar de mencionar que a asseguração da disciplina jurídica originou-se, em muitas oportunidades, de processos revolucionários. Mas mesmo nessas ocasiões a codificação tornou-se produto da ideologia conservadora, na medida em que o estabelecimento de óbices ao acompanhamento da evolução social e da mudança dos processos de convivência na modernidade distanciaram o direito da pretensão de realização da justiça.

A instrumentalidade do Direito, assim, foi decisiva para o estabelecimento de seu caráter liberal-racionalista. A história firmou o apego excessivo do direito ao formalismo, ao procedimento, aproximando-o da logicidade. A certeza passou a ser um sujeito presente no cerne de todo debate envolvendo a

${ }^{58}$ BAPTISTA DA SILVA, Ovídio Araújo. Jurisdição e Execução na Tradição Romano-Canônica. Rio de Janeiro: Forense, 2008. p. 105.

${ }^{59}$ WIEACKER, Franz. História do Direito Privado Moderno. p. 309.

60 TARELLO, Giovanni. Cultura Jurídica y Política del Derecho. Traducción de Isidro Rosas Alvarado. México: Fondo de Cultura Económica, 1995. p. 40. 
Ciência Jurídica. Como afirma Chiovenda, "la certezza del diritto, imponendosi alle menti di tutti, accresce, come vedemmo, la sua importanza sociale". ${ }^{61}$

A retomada da personalidade dos indivíduos, da idéia de rechaçamento do processo de esteriotipação, do enquadramento classístico, político, profissional e sexual, constituem-se em pressupostos de superação do caráter excludente do liberalismo. O reconhecimento da individualidade enquanto constituinte da sociedade, que produz diferenças que firmam o pluralismo e o combate à igualdade estrutural, que intenta a manutenção do status quo, também se firmam como condições de superação do liberalismo que funda a modernidade líquida descrita por Bauman.

A Jurisdição, por sua vez, também associada ao modelo liberal, só será protagonista de um ordenamento que gere inclusão na medida em que romper com o dogmatismo, ainda alicerçado na actio romana e motivador da repetição sintomática da jurisprudência, aproximando-se da autenticidade jurisdicional e do conceito de sentença concebido por Liebman, definida como ato de intelectivo.

As decisões, na verdade, constituem-se hoje num produto da tecnologia jurídica, da era da técnica, da massificação de procedimentos e do tolhimento da personalidade das demandas. O Direito fez uma clara opção de exclusão do indivíduo e de generalização procedimental, esquecendo-se que as demandas fundam-se nos desejos e nas pretensões de pessoas, não se constituindo no fruto do acaso ou em mais uma engrenagem do Estado burocrático.

\section{REFERÊNCIAS BIBLIOGRÁFICAS}

ARENDT, Hannah. A Condição Humana. Traduzido por Roberto Raposo. Rio de Janeiro: Forense-Universitária, 1987.

BAPTISTA DA SILVA, Ovídio Araújo. Jurisdição e Execução na Tradição RomanoCanônica. 2. ed. rev. Rio de Janeiro: Forense, 2008.

${ }^{61}$ CHIOVENDA, Giuseppe. Saggi di Diritto Processuale Civile. Milano: Giuffrè, 1993. Volume Terzo. p. 67. Em outra passagem, Chiovenda esclarece esse pensamento, aduzindo que "questa produzione della certezza giuridica come fine a se stessa è da un lato la funzione più autonoma del processo, perché procaccia un bene non altrimenti conseguibile: dall'altro è veramente la funzione più elevata del processo civile. Esso ci si presenta qui, non come un organismo di coazione, ma nell'aspetto più perfezionato e più raffinato di puro strumento di integrazione $\mathrm{e}$ specializzazione della volontà, che è espressa nella legge sollo in forma generale ed astratta; di facilitazione della vita sociale mediante l'eliminazione dei dubbi che intralciano il normale svolgimento dei rapporti giuridici. Assicurare alle relazione degli uomini la certezza, prevenire gli atti illegittimi anziché colpirli col peso di gravi responsabilità, ecco un compito bem degno del processo di un popolo civile". "esta produção da certeza jurídica como fim em si mesma é de um lado a função mais autônoma do processo, porque busca um bem não alcançável de outro modo: por outro lado, é verdadeiramente a função mais elevada do processo civil. Isso apresenta-se aqui, não como um organismo de coação, mas no aspecto mais aperfeiçoado e mais refinado de puro instrumento de integração e especialização da vontade, que se expressa na lei apenas de forma geral e abstrata; de facilitação da vida social mediante a eliminação das dúvidas que impedem o normal desenvolvimento das relações jurídicas. Assegurar às relações humanas a certeza, preverir os atos ilegítimos ao invés de atacá-los com o peso de grave responsabilidade, aí está uma tarefa muito nobre do processo de um povo civilizado." 
BIONDI, Biondo. Universalità e Perennità della Giurisprudenza Romana. In: L'Europa e il Diritto Romano. Vol. II. Milano: Giuffrè, 1954.

CASSIRER, Ernst. A Filosofia do Iluminismo. Traduzido por Álvaro Cabral. Campinas: Unicamp, 1992.

Linguagem e Mito. Traduzido por J. Guinsburg e Miriam Schnaiderman. 3. ed. São Paulo: Perspectiva, 1992b.

CHIOVENDA, Giuseppe. Saggi di Diritto Processuale Civile. Volume Terzo. Milano: Giuffrè, 1993.

CITTADINO, Gisele. Pluralismo, Direito e Justiça Distribuitiva. Elementos da Filosofia Constitucional Contemporânea. 2 ed. Rio de Janeiro: Lúmen Júris, 2000.

DURANT, Will. A História da Filosofia. Rio de Janeiro: Nova Cultural, 1997.

DWORKIN, Ronald. Uma Questão de Princípio. Traduzido por Luís Carlos Borges. São Paulo: Martins Fontes, 2001.

. O império do Direito. Traduzido por Jefferson Luiz Camargo. São Paulo:

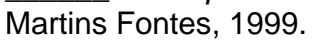

. Los Derechos en Serio. Traduzido por Marta Guastavino. Barcelona: Ariel, 1984.

ENGISCH, Karl. Introdução ao Pensamento Jurídico. Traduzido por J. Baptista Machado. 6. ed. Lisboa: Fundação Calouste Gulbenkian, 1996.

ESPINDOLA, Angela Araujo da Silveira. A Crise Conceitual e a (re) Construção Interrompida da Soberania: O Fim do Estado-Nação? In: MORAIS, José Luis Bolzan (org). O Estado e suas Crises. Porto Alegre: Livraria do Advogado, 2005.

FEDERICI, Mario. Las Transformaciones Finiseculares del Estado. Foro Político. Revista Del Instituto de Ciências Políticas. Cátedra Ortega. Universidade del Museo Social Argentino. Volumen XXVIII, abril, 2000.

GIL, Antonio Hernández. Problemas Epistemológicos de la Ciencia Jurídica. 2. ed. Madrid: Civitas, 1981.

GRAMSCI, Antonio. Cadernos do Cárcere. Rio de Janeiro: Civilização Brasileira, 1999-2002.

HAYEK, Friedrich A. von. O Caminho da Servidão. Tradutores/Revisores: Anna Maria Capovilla; José Italo Stelle; Liane De Morais Ribeiro. Rio de Janeiro: Instituto Liberal, 1984.

KAUFMANN, Arthur; HASSEMER, Winfried (Org.). Introdução à Filosofia do Direito e à Teoria do Direito Contemporâneas. Traduzido por Marcos Keel e Manuel Seca de Oliveira. Lisboa: Calouste Gulbenkian, 2002.

KUHN, Thomas S. A Estrutura das Revoluções Científicas. Traduzido por Beatriz Vianna Boeira e Nelson Boeira. 5. ed. São Paulo: Perspectiva, 1997.

LARENZ, Karl. Metodologia da Ciência do Direito. Tradução da $6^{a}$ edição de José Lamego. 3. ed. Lisboa: Calouste Gulbenkian, 1997.

MACINTYRE, Alasdair. A Short History of Ethics: A History of Moral Philosophy from the Homeric age to the Twentieth Century. 2. ed. London: Routledge, 1998.

MARRAMAO, Giacomo. Céu e Terra. Traduzido por Guilherme Alberto Gomez de Andrade. São Paulo: UNESP, 1997. 
MONTESQUIEU. O Espírito das Leis. Traduzido por Luiz Fernando de Abreu Rodrigues. Textos selecionados. Curitiba: Juruá, 2001.

PERELMAN, Chaïm; OLBRECHTS-TYTECA, Lucie. Tratado da Argumentação. Traduzido por Maria Ermantina Galvão G. Pereira. São Paulo: Martins Fontes, 1996.

PLATÃo. Crátilo. Diálogo sobre a Justeza dos Nomes. Traduzido por Pe. Dias Palmeira. 2. ed. Lisboa: Sá da Costa Editora, 1994.

RADBRUCH, Gustav. Filosofia do Direito. Traduzido por L. Cabral de Moncada. 6. ed. ver. Coimbra: Armênio Amado, 1979.

RAWLS, John. Uma Teoria da Justiça. Traduzido por Almiro Pisetta, Lenita Maria Rímoli Esteves. 2. ed. São Paulo: Martins Fontes, 2002.

ROCHA, Leonel Severo. Epistemologia Jurídica e Democracia. 2. ed. São Leopoldo: UNISINOS, 2003.

ROSSEAU, Jean Jacques. O Contrato Social. Traduzido por Antonio de Pádua Danesi. 3.ed. São Paulo: Martins Fontes, 1996.

SANDEL, Michael. Democracys Discontent. América in Search of a Public Philosophy. Cambridge: Harvard University Press, 1996.

SPENGLER, Fabiana Marion. Crise Funcional: Morte ou Transformação do Estado? In: MORAIS, José Luis Bolzan (org). O Estado e suas Crises. Porto Alegre: Livraria do Advogado, 2005.

STRECK, Lenio Luiz; MORAIS, José Luis Bolzan. Ciência Política e Teoria do Estado. 5 ed. Porto Alegre: Livraria do Advogado, 2006.

TAYLOR, Charles. El Multiculturalismo y la Política del Reconocimiento. Traduzido por Mônica Utrilla de Neira. México: Fondo de Cultura Econômica, 1993.

TARELLO, Giovanni. Cultura Jurídica y Política del Derecho. Traducción de Isidro Rosas Alvarado. México: Fondo de Cultura Económica, 1995.

WALZER, Michael. Das Obrigações Políticas: Ensaios sobre Desobediência, Guerra e Cidadania. Traduzido por Helena Maria Camacho Martins Pereira. Rio de Janeiro: Zahar, 1977.

WIEACKER, Franz. História do Direito Privado Moderno. Traduzido por A. M. Botelho Hespanha. 2. ed. Lisboa: Calouste Gulbenkian, 1967. 